\title{
Resolução de Problemas na Matemática Financeira para Tratamento de Questões da Educação Financeira no Ensino Médio
}

\author{
Problem Solving in Financial Mathematics for the Treatment of Financial \\ Education Matters in High School
}

\author{
Clístenes Lopes da Cunha* \\ João Bosco Laudares**
}

\begin{abstract}
Resumo
Neste artigo, originado de uma Dissertação de Mestrado, apresentamos recortes de uma pesquisa cujo objetivo foi a educação financeira, abordada com atividades que enfocaram conceitos e cálculos da Matemática Financeira, com questões imersas em valores socioeconômicos. Adotamos a metodologia da resolução de problemas de Polya (2006), Dante (2009), entre outros, o que possibilitou não só trabalhar com modelos da Matemática Financeira mas, vivenciar na escola questões econômicas, sociais e políticas. Usamos os parâmetros da Matemática Financeira de Puccini (2007). Referenciamos em vários acadêmicos, integrantes do grupo de pesquisa em Matemática Financeira da Universidade Federal de Juiz de Fora (UFJF) e coordenados pelo Dr. Marco Aurélio Kistemann Junior. Como suporte para educação financeira e tomada de decisão. Os conteúdos da Matemática explorados foram funções e progressões, com abordagem interdisciplinar. Os sujeitos foram estudantes do Ensino Médio na Educação Básica. Foram construídas cinco atividades com problemas, abordando conceitos e cálculos financeiros, a partir das temáticas como poupança e financiamentos. Aqui, apresentamos a análise de duas questões das atividades um e dois. Pela análise de erros, ficou evidenciada uma contínua melhora da postura reflexiva do estudante, não só na resolução dos problemas financeiros pelos cálculos efetuados, mas pela interpretação das proposições em estudo. Esses resultados obtidos, resolução e interpretação, confirmaram a eficiência da metodologia empregada.
\end{abstract}

Palavras-chave: Educação Financeira. Matemática Financeira. Resolução de Problemas.

\begin{abstract}
In this article, which originated from a Master's Dissertation, we present the results of a research, which objective was financial education, approached with activities that focused on concepts and calculations of financial mathematics, with questions immersed in socioeconomic values. We adopted the methodology of problem solving by Polya (2006), Dante (2009) among others, which allowed us not only to work with models of financial mathematics but to experience economic, social, and political issues in school. We use the parameters of the financial mathematics of Puccini (2007). We refer to several academics, members of the research group in Financial Mathematics as support for financial education and decision making, from Universidade Federal de

\footnotetext{
* Mestre em Educação Matemática pela Pontifícia Universidade Católica (PUC/Minas). Professor do ensino Básico, Técnico e Tecnológico no Centro Federal de Educação Tecnológica de Minas Gerais (CEFET/MG.), Belo Horizonte/MG, Brasil. Endereço para correspondência: R. Aparecida Feitosa Furtado, 186/102, Barreiro, Belo Horizonte/MG. CEP: 30.627-205. E-mail: clístenescunha@yahoo.com.br.

** Doutor em Educação pela Pontifícia Universidade Católica (PUC/SP). Professor no Ensino Superior na Pontifícia Universidade Católica (PUC/Minas), Belo Horizonte/MG, Brasil. Endereço para correspondência: Rua Jornalista Moacir Andrade, 192, Bairro São Bento, Belo Horizonte/MG. CEP: 30.350.410. E-mail: jblaudares@terra.com.br.
} 
Juiz de Fora (UFJF), which is coordinated by Dr. Marco Aurélio Kistemann Junior. The explored contents of mathematics were functions and progressions, with an interdisciplinary approach. The subjects were high school students in basic education. Five activities were built with problems, approaching concepts, and financial calculations, from subjects such as savings and financing. Here, we present the analysis of two questions from activities one and two. Through the analysis of errors, a continuous improvement of the student's reflexive posture was evidenced, not only in the resolution of the financial problems by the calculations made, but also in the interpretation of the propositions under study. The results, resolutions, and interpretations obtained, confirmed the efficiency of the methodology used.

Keywords: Financial Education. Financial Mathematics. Solving Problems.

\section{Introdução}

Neste artigo, originado de uma dissertação de mestrado, apresentamos recortes de uma investigação dentro de uma proposta de Educação Financeira. Esta é definida no campo da Educação Matemática por parâmetros didáticos, enfocando os conceitos e cálculos da Educação Financeira, a partir de abordagens reflexivas de questões em situações da realidade sócio-política brasileira, imersa em valores econômicos do cotidiano do estudante.

Trouxemos aportes de um referencial teórico, a partir do objeto e da problematização da pesquisa, quanto à resolução de problemas, a Matemática Financeira e a Educação Financeira. Adotamos a metodologia da resolução de problemas de Polya (2006), Dante (2009), entre outros, e de Puccini (2007), quanto aos parâmetros da Matemática Financeira.

Há grupos emergentes de estudo e pesquisa em Educação Financeira, como o da Universidade Federal de Juiz de Fora de Minas Gerais - UFJF/MG, já com significativa produção nesta temática, a partir da problematização de conceitos financeiros e da relação com questões de Educação Matemática. Citamos alguns componentes do grupo evidenciado nos quais nos referenciamos, como Kistemann (2011), Resende (2012), Brito (2012), Bernardo Campos (2013) e Bergamini Campos (2013).

Os sujeitos da investigação foram estudantes do Ensino Médio que trabalharam com as atividades de funções e progressões do conteúdo programático de Matemática desse nível de ensino.

A problematização se fez buscando resposta a seguinte pergunta: Como promover a Educação Financeira de forma significativa a partir da resolução de problemas da Matemática Financeira na Educação Básica, especificamente no Ensino Médio? E, para buscarmos responder a esse questionamento, trabalhamos com a Matemática Financeira, a partir da resolução de problemas, por meio de atividades de cunho econômico-financeiro, buscando parâmetros que contribuíssem para uma formação do estudante na realidade de uma sociedade capitalista, a exigir cada vez mais o econômico na vida social dos indivíduos. 
Para alcançarmos os objetivos da pesquisa do desenvolvimento da Educação Financeira, criamos situações bem próximas da vida social e econômica que os estudantes vivem atualmente. Assim, identificamos atividades que promovessem compreensão e fossem instrumentos de investigação em Matemática Financeira com problemas envolvendo diversas temáticas como: poupança, cálculos trabalhistas, prestações, financiamentos de imóveis e aquisição de veículos.

A metodologia de resolução de problemas trouxe questionamentos como instrumento de investigação, para promover um ensino e aprendizagem de Matemática para educação crítica cidadã, pois, hoje, vivemos numa sociedade capitalista que se conforma por parâmetros sociais e econômicos.

Os temas foram tratados com cálculos e debates em situações da vida econômica, usando diversas representações como gráficos, tabelas e fórmulas, para favorecer a interpretação, acompanhada dos cálculos inerentes às questões suscitadas.

Das atividades propostas na pesquisa, analisamos aqui a questão 4 da atividade 1: Estudo sobre algumas formas de poupar, e a questão 7 da atividade 2: Seguro-desemprego.

\section{Conceituação de Educação Financeira a partir da Matemática Financeira}

Com os conteúdos da Matemática Financeira trabalhados na escola, com memorização de fórmulas e situações que não retratam a realidade, surgem dificuldades para o estudante na aplicação de conceitos e na operacionalização de cálculos, especialmente na resolução de problemas.

Segundo Rosetti Jr. e Schimiguel (2009), há necessidade de repensar a didática, estritamente matemática, para o tratamento de temáticas que suscitem possibilidades de questionamentos do mundo real dos alunos, pois muitas vezes os "conteúdos de matemática comercial e financeira que são trabalhados atualmente com alunos do ensino médio e de ensino técnico não atendem às demandas dos estudantes e do mundo do trabalho." (2009, p. $11)$.

Com relação à Matemática Financeira, Puccini (2007) destaca o seu amplo campo de aplicação, no qual

suas técnicas são necessárias em operações de financiamento de quaisquer naturezas: crédito a pessoas físicas e empresas, financiamentos habitacionais, crédito direto ao consumidor e outras. Também são necessárias em operações de investimentos mobiliários nos mercados de capitais. Em ambas as situações, é o uso dessas técnicas que permite conhecer o custo e o retorno dessas operações, permitindo tomadas de decisão mais racionais; são elas também que permitem 
determinar o valor das prestações devidas pelas transações efetuadas em parcelas. No mundo dos negócios, seu conhecimento é absolutamente imprescindível, uma vez que os custos dos financiamentos dados e recebidos são peças centrais do sucesso empresarial (PUCCINI, 2007, p. 8).

Para a efetivação de Educação Financeira, há necessidade de uma transição do ensino da Matemática Financeira, para o exercício da reflexão e crítica acerca de situações que influenciam a vida financeira das pessoas, não se limitando a simples aplicações de fórmulas de juros simples ou compostos ou outros cálculos mais sofisticados.

A Educação Financeira, a partir da Matemática Financeira, tem um objetivo formativo, voltado para um compromisso educacional, pois, segundo Lima e Sá (2010, p. 5),

\footnotetext{
ensinar matemática financeira para as crianças não é só ensiná-las a lidar com o dinheiro, mas sim fazer com que elas rejeitem a corrupção, façam negociações justas, cumpram prazos e valores combinados, tenham consciência ambiental usando sem desperdiçar os recursos naturais, tendo um pensamento coletivo e humanitário e, por fim, que sejam responsáveis socialmente.
}

Em uma sociedade capitalista há a busca do consumo pelo consumo, o qual, muitas vezes, não reflete a realização de necessidades, mas o puro acúmulo de produtos para a maisvalia do capital. Numa abordagem sociológica, educamos o trabalhador para uma consciente aquisição de processos e produtos inerentes à sua necessidade de vida com valor de uso, pois ao capital interessa mais o valor de troca, com incentivo ao consumo não consciente e, consequente acúmulo de lucros financeiros e de valor econômico.

Uma das funções da escola é preparar o indivíduo para o exercício da cidadania, propiciando condições para a sua formação de uma consciência social e política, vivendo numa sociedade de capitalismo selvagem, cujo objeto é, estritamente, obtenção de lucro econômico e financeiro.

A educação financeira pode ser um instrumento para contrapor este paradigma, com questionamentos pela resolução de problemas, com o que corroboram Rosetti Jr. e Schimiguel (2009, p.2) ao proporem que a escola, por seus currículos, busque o desenvolvimento de "competências e habilidades que propiciem uma postura autônoma diante dos problemas a serem enfrentados".

A Educação Financeira trabalha com a aquisição de algoritmos e fórmulas, mas de uma maneira situada para problematizar o contexto socioeconômico "não devendo, também, ser confundida com um manual de regras moralistas fáceis" (OLIVEIRA, 2007, p. 9). 
Os textos da Estratégia Nacional de Educação Financeira - $\mathrm{ENEF}^{1}$ - (2010) trazem noções para compreensão do conceito de Educação Financeira como

\begin{abstract}
-processo mediante o qual os indivíduos e as sociedades melhoram sua compreensão em relação aos conceitos e produtos financeiros, de maneira que, com informação, formação e orientação, possam desenvolver os valores e as competências necessários para se tornarem mais conscientes das oportunidades e dos riscos nele envolvidos e, então, poderem fazer escolhas bem informadas, saber onde procurar ajuda, adotar outras ações que melhorem o seu bem-estar. Assim, podem contribuir de modo mais consciente para a formação de indivíduos e sociedades responsáveis, comprometidos com o futuro (BRASIL, 2010, p. 57-58).
\end{abstract}

Um trabalho na multi ou interdisciplinaridade produz suportes para um movimento da Matemática Financeira em direção à Educação Financeira, a ser tratada em todos os níveis de escolaridade, da Educação Básica à Superior.

Para contribuir com este movimento, desenvolvemos uma pesquisa no Ensino Médio, com atividades estruturadas para conduzir alunos e professores e um envolvimento dos conteúdos matemáticos e suas aplicações em algumas situações econômico-financeiras.

\title{
3 Atividades de Educação Financeira e a resolução de problemas
}

Durante toda a formação escolar, pretendemos que o aluno desenvolva competências sociais e profissionais, a partir dos estudos que vão aumentando de grau de complexidade, à medida que os mesmos vão sendo promovidos nos diversos graus de ensino. Dessa maneira, lhes são apresentados conteúdos e problemas matemáticos que vão requerendo um acúmulo de conhecimento.

Identificando o contexto no qual os alunos se formam, vislumbramos um mundo globalizado que exige tomadas de decisões extremamente rápidas e simplificadas, tanto na execução, quanto na transmissão dos acertos destas decisões para outras diferentes situações.

Uma alternativa para inserção neste contexto e aprendizagem de tomada de decisão é a resolução de problemas, que exige uma construção organizacional e argumentativa necessária para gerenciar dados numa estrutura, que sempre está presente numa problematização.

Adotamos na nossa investigação parâmetros de pesquisadores da metodologia de resolução de problemas, apresentados a seguir.

Dante (2009, p. 18-23) elenca algumas particularidades existentes em sala de aula, que resumimos assim:

\footnotetext{
${ }^{1}$ A ENEF foi desenvolvida em parceria do governo com a iniciativa privada e a sociedade civil, buscando promover e fomentar a cultura de Educação Financeira no país, ampliar a compreensão do cidadão, para que seja capaz de fazer escolhas conscientes quanto à administração de seus recursos, e contribuir para a eficiência e solidez dos mercados financeiro, de capitais, de seguros, de previdência e de capitalização (BRASIL, 2010, p. 2).
} 
- Fazer o aluno pensar produtivamente: motiva a desenvolver o pensamento produtivo e não reprodutivo.

- Desenvolver o raciocínio do aluno: para utilizar, de forma eficaz, os recursos de que dispõe, proporcionando-lhe boas soluções para as questões do cotidiano.

- Ensinar o aluno a enfrentar situações novas: para a adaptação às situações do mundo atual, são necessários a iniciativa, espírito explorador e a criatividade.

- Dar ao aluno a oportunidade de se envolver com as aplicações da Matemática: em contraposição ao treino de algoritmos, podemos usar os conceitos e procedimentos vinculados com situações do dia a dia, evitando o "para que serve isso?".

- Tornar as aulas de Matemática mais interessantes e desafiadoras: acompanha o prazer da descoberta.

- Oferecer ao aluno estratégias para resolver problemas: auxilia a análise e a solução de situações em que um ou mais elementos desconhecidos são procurados.

- Dar uma boa base matemática: o aluno deve ter subsídios para enfrentar situaçõesproblema que o preparem para resolver problemas domésticos de economia, administração, engenharia, medicina, previsão do tempo e outros da vida diária.

- Liberar a criatividade do aluno: a formulação e resolução de problemas exigem o pensamento produtivo do aluno e aumenta a probabilidade da criatividade se manifestar.

Para Echeverría e Pozo (1988, p. 9), a solução de problemas “oferece ao aluno situações abertas e sugestivas que exijam uma atitude ativa ou um esforço para buscar suas próprias respostas, seu próprio conhecimento".

Dentre as técnicas de trabalho com solução de problemas e no enfrentamento de situação-problema, temos a perspectiva metodológica ${ }^{2}$ de "Ensino-Aprendizagem de Matemática, a Resolução de Problemas" (ONUCHIC e ALLEVATO, 2012), e que, segundo Diniz (2001, p. 89)

baseia-se na proposição e no enfrentamento do que chamaremos de situaçãoproblema. Isto é, ampliando o conceito de problema, devemos considerar que a Resolução de Problemas trata de situações que não possuem solução evidente e que exigem que o resolvedor combine seus conhecimentos e decida pela maneira de usálos em busca da solução.

Segundo Polya (2006, p. 4), “a Resolução de Problemas é uma habilitação prática como, digamos, o é a natação. Adquirimos qualquer habilitação por imitação ou prática”.

\footnotetext{
2 Perspectiva metodológica foi o termo utilizado por Maria Ignez Diniz no livro "Ler, escrever e resolver problemas: habilidades básicas para aprender matemática" (DINIZ, 2001b, p. 99), para que pudesse enquadrar sua concepção de Resolução de Problemas.
} 
Segundo o mesmo autor, cabe ao professor incitar os estudantes para a iniciativa de solucionar problemas, imitando o que o mesmo fizera anteriormente, o uso dos conhecimentos prévios.

Ainda, segundo Echeverría e Pozo (1988), o ato de apresentar aos alunos os procedimentos de resolução de problemas "não consiste somente em dotar os alunos de habilidades e estratégias eficazes, mas também em criar neles o hábito e a atitude de enfrentar a aprendizagem como um problema para o qual deve ser encontrada uma resposta" (1988, p. $14)$.

Assim, pretendemos que o aluno busque problemas para a discussão em sala, trazendo consigo dados, textos e algumas conclusões que seriam testadas pelos demais colegas e pelo professor. É um movimento que retira do centro da aula o professor e realoca o aluno como agente construtor do próprio conhecimento (ONUCHIC e ALLEVATO, 2012). O aluno começa a perceber que consegue aprender quando tem de buscar respostas e mecanismos para responder às suas próprias dúvidas.

A proposta de ressignificar a Matemática Financeira no Ensino Médio, passando pela Educação Financeira junto à resolução de problemas, busca possibilidades para que o estudante adentre no mundo financeiro e no real significado da escola, que é preparar e formar o cidadão. Em nossa concepção, essa formação só se dá pelo uso do conhecimento adquirido, em forma de habilidades e competências, para mudança da realidade do próprio indivíduo e, consequentemente, da microssociedade em que vive.

Trazendo para a sala de aula exemplos que possibilitem o trabalho com alguns conceitos e cálculos com algoritmos de Matemática Financeira apresentamos cinco temas, em forma de atividades, que nortearam nosso estudo:

- Atividade 1: Estudo sobre algumas formas de poupar

- Atividade 2: Estudo de casos de cálculos trabalhistas

- Atividade 3: Cálculo de prestações constantes

- Atividade 4: Atenção aos financiamentos de imóveis - tabela SAC e algumas taxas

- Atividade 5: Alguns meios de aquisição de veículos: leasing, CDC e consórcio

Tais atividades seguiram dois parâmetros para sua escolha, questionamentos dos alunos acerca de temas do cotidiano que possivelmente são abordados pela Matemática Financeira e o condicionamento desses temas aos conteúdos de Matemática do Ensino Médio.

Optamos pelo uso de calculadoras científicas em nossas atividades, para minimizarmos a morosidade das operações e focarmos na interpretação de conceitos trabalhados (NASSER, 2009). 
Essas calculadoras já existem em grande maioria em aplicativos para celulares, principalmente nos de tecnologia mais recente e, por isso, estão ao alcance de muitos brasileiros, dentre eles os estudantes do Ensino Médio, jovens entre 14 e 19 anos de idade. Segundo dados da Agência Nacional de Telecomunicação - Anatel, o Brasil terminou maio de 2015 com cerca de 280 milhões de celulares, sendo 140 celulares por 100 habitantes.

Em sala de aula, optamos pelo trabalho em duplas para que ocorressem momentos de discussão mais fecunda, em que o aluno pudesse defender o seu ponto de vista, extraindo elementos dos textos, vinculando-os a conceitos matemáticos para construir sua argumentação, inicialmente perante seu parceiro, para, posteriormente, levar suas ideias à sala.

Segundo Ponte, Boavida e Abrantes (1997), o discurso oral, escrito ou gestual existe em toda relação de ensino-aprendizado. Para esses autores, a comunicação oral tem destaque importante no ensino de Matemática, pois "ela é imprescindível para que os alunos possam exprimir as suas ideias e confrontá-las com as dos seus colegas" (PONTE, BOAVIDA e ABRANTES, 1997, p. 14).

Nessa dinâmica de aula, o aluno teve o papel de questionador. De alguma forma, deveria relacionar o que havia lido no texto inicial com as atividades apresentadas e ainda ter alguma noção de situações econômico-financeiras. Em muitos momentos, o professor era chamado aos grupos para esclarecer algumas dúvidas.

As respostas dadas pelo professor não passavam de orientações como as utilizadas por Polya (2006, p. 17), em o Método de Questionar do Professor, no qual "as sugestões devem ser simples e naturais, porque do contrário elas não poderiam ser discretas.”. O autor ainda comenta que elas "devem ser genéricas, aplicáveis não apenas ao problema presente, mas também a problemas de todos os tipos, pois só assim elas poderão desenvolver a capacidade do estudante e não somente uma técnica específica.".

Alguns problemas abertos, que tinham dupla interpretação ou texto pouco objetivo, foram agregados de maneira a suscitar nos alunos um posicionamento crítico. Deveriam levar em consideração também as variáveis subjetivas, que surgem pela conjuntura entre a sua disponibilidade de capital no momento, as condições legais e comerciais e o período para a transação financeira.

Nossa análise foi qualitativa para alcançar todas as nuanças da resolução pelos estudantes, agregando à mesma alguns dados quantitativos tratados com percentagem na análise de erros. 


\section{Análise das respostas}

As observações dos pesquisadores (relatório de pesquisa) foram feitas apenas num Caderno de Anotações, pois a instituição de ensino, que é privada e confessional, não permitiu fotografias, gravações ou filmagens dos alunos nas dependências da escola. Representamos os nomes das duplas pelas iniciais de cada componente, por exemplo: Augusto e José, Grupo AJ.

Para a análise de dados, elencamos cinco tipos de erros, baseados nos Eixos Cognitivos presentes na Matriz de Referência para o Novo ENEM (BRASIL, 2009), e nas demandas específicas da promoção do pensamento crítico matemático pela educação financeira, adequados às quatro fases de trabalho para resolução de problemas de Polya (2006, p. 4-5): compreensão do problema, plano de resolução, execução do plano e retrospecto da resolução completa.

1. Erro de incompreensão do texto introdutório: erro que se refere à habilidade de domínio da linguagem (DL) interferindo na compreensão da situação-problema, proposta por um texto informativo inicial.

2. Erro de incompreensão da situação-problema: erro referente ao enfrentamento de situações-problema (SP) por meio de um plano de resolução incorreto, que inviabiliza toda uma dinâmica de resolução coerente.

3. Erro do emprego de fórmulas/conceitos: erro oriundo da construção de argumentação (CA), execução do plano de resolução. É característico do conteúdo de matemática financeira, e ficam mais evidentes nas relações entre tempo, dinheiro e porcentagens.

4. Erro operacional no emprego de fórmulas/conceitos: remete a alguma defasagem de conteúdos básicos ou desatenção com relação aos passos operacionais para a resolução do problema.

5. Erro na interpretação crítica na conclusão: erro referente à elaboração de propostas (EP) coerentes para a situação apresentada. De forma retrospectiva, o aluno faz uma varredura em seus cálculos, inclusive relendo os textos da questão para adequar sua análise final aos procedimentos usados.

Pedimos atenção ao fato de que cometer um erro operacional, por exemplo, não significa o comprometimento de toda a interpretação da situação, podendo, mesmo assim, produzir coerentemente um retrospecto de resolução completa. Quando resolvemos uma questão, projetamos um percurso para nossa ação e uma provável resposta, a formulação de uma conjectura, que pode se confirmar mesmo com pequenos erros de processo. Desta forma, 
permitimos aos alunos que prosseguissem com a resolução das questões mesmo que em alguma parte cometessem algum erro.

A seguir, exemplificamos a nossa análise de erro, por meio de duas questões selecionadas, respectivamente da atividade 1 (um) e 2 (dois) da pesquisa realizada.

\section{Análise da questão 4 da atividade 1: estudo sobre algumas formas de poupar}

Selecionamos para apresentar a questão 4 (quatro) da primeira atividade, para ilustrarmos de forma mais clara e sucinta o que pretendíamos com nossa pesquisa, que envolve conceitos de Matemática Financeira aplicados ao cotidiano dos alunos e, como podemos avaliar suas respostas, na busca por uma educação crítica voltada à promoção da cidadania. Essa questão foi trabalhada em duas aulas de cinquenta minutos cada e exigia conhecimentos prévios sobre Juros Compostos, Função Exponencial e Progressão Geométrica.

O texto norteador, “Qual seria a melhor escolha, Poupança ou CDB-DI?”, explicava as diferenças entre essas duas modalidades de investimento, levando em conta a cobrança do Imposto sobre Operações Financeiras (IOF), incidência do Imposto de Renda de Pessoa Física (IRPF) e rentabilidade.

Com relação ao conteúdo matemático que trata de financiamentos, fizemos a seguinte pergunta:

Antônio pretende aplicar certa quantia todo mês para que no final de um ano tenha um montante suficiente para viajar com sua família para sua cidade natal no interior de Minas Gerais. Resolveu depositar mensalmente $R \$ 100,00$ na Caderneta de Poupança, com expectativa de rendimento em torno de 0,5\%.

a) Veja como completamos a tabela para determinar esse valor. Que conteúdo matemático você percebe com relação aos valores em negrito nos meses 2,3 e 4 ?

Tabela 1 - Evolução no tempo do rendimento da poupança para depósitos fixos

\begin{tabular}{ccc}
\hline MESES & OPERAÇÄO (RS) & MONTANTE (RS) \\
\hline 1 & 100 & 100,00 \\
2 & $100+100 \times 1,005=100 \times(1+1,005)$ & 200,50 \\
3 & $100+[100 \times(1+1,005)] \times 1,005=100 \times\left(1+1,005+1,005^{2}\right)$ & 301,50 \\
4 & $100+\{[100 \times(1+1,005)] \times 1,005\} \times 1,005=100 \times\left(1+1,005+1,005^{2}+1,005^{3}\right)$ & 403,01 \\
$\cdots$ & $\ldots$ & $\cdots$ \\
12 & & \\
\hline
\end{tabular}

Fonte: Elaborado pelos autores (2013) 
Esse item obteve $100 \%$ de acerto, ocorrendo, inclusive, grupos que conseguiram perceber a existência de um caráter de sequência nos valores, apontando para uma progressão geométrica, relacionando conteúdos matemáticos.

$$
\text { Semeltante a suma soma de } P G \text {, multiplivado por } 100 \text { e de razas 1,005. }
$$

Figura 1 - Resposta à Atividade 1, questão 4 (a) Fonte: Grupo AY (2013)

A redação do extrato apresentado na Figura 1 é: "Semelhante a uma soma de PG, multiplicada por 100 e de razão 1,005".

No item b, levamos os alunos a relacionarem juros compostos, progressão geométrica e função exponencial, mas observamos um grave problema quando relacionamos o grau de acerto do item (a) com os erros dos itens seguintes, principalmente do item (b), em que o aluno tinha que completar uma tabela para produzir um gráfico exponencial, observando o padrão da sequência.

b) Construa um gráfico representativo com os valores encontrados para a tabela abaixo.

A tabela em geral foi bem compreendida no contexto de juros compostos, vinculado ao uso de progressão geométrica, mas no traçado do gráfico erraram, pois não perceberam o caráter exponencial que ele traz. Muitos dos erros também podem ser atrelados ao uso de escalas incorretas, atribuindo ao gráfico um modelo linear, como na figura a seguir:

\begin{tabular}{|c|c|}
\hline MESES & MONTANIE (RS) \\
\hline 1 & 100,00 \\
2 & 200,50 \\
3 & 301,50 \\
4 & 403,01 \\
5 & 505,02 \\
6 & 607,55 \\
7 & 710,58 \\
8 & 814,19 \\
9 & 918,21 \\
10 & $1.022,80$ \\
11 & $1.123,14$ \\
12 & $1.233,55$ \\
\hline
\end{tabular}

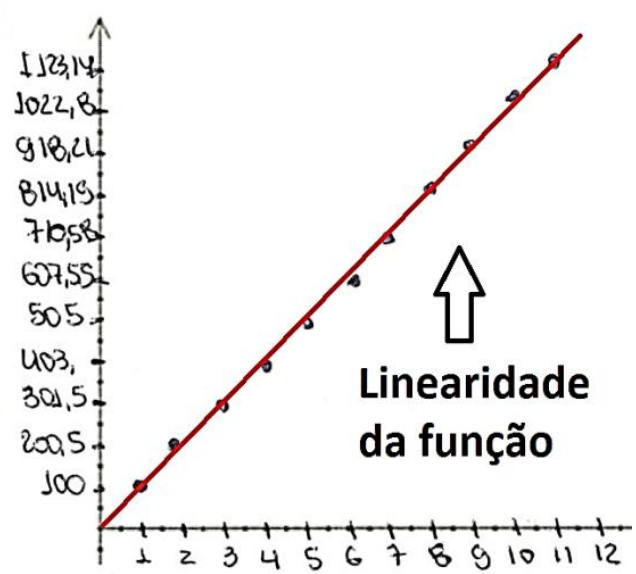

Figura 2 - Resposta à Atividade 1, questão 4 (b) Fonte: Grupo SR (2013)

Apresentamos a seguir o gráfico de erros (Figura 3) e percebemos que, mesmo o aluno, não compreendendo bem o texto introdutório, conseguiu trabalhar a situação-problema, apresentando, todavia, baixo índice de compreensão do conteúdo matemático a ser utilizado. 


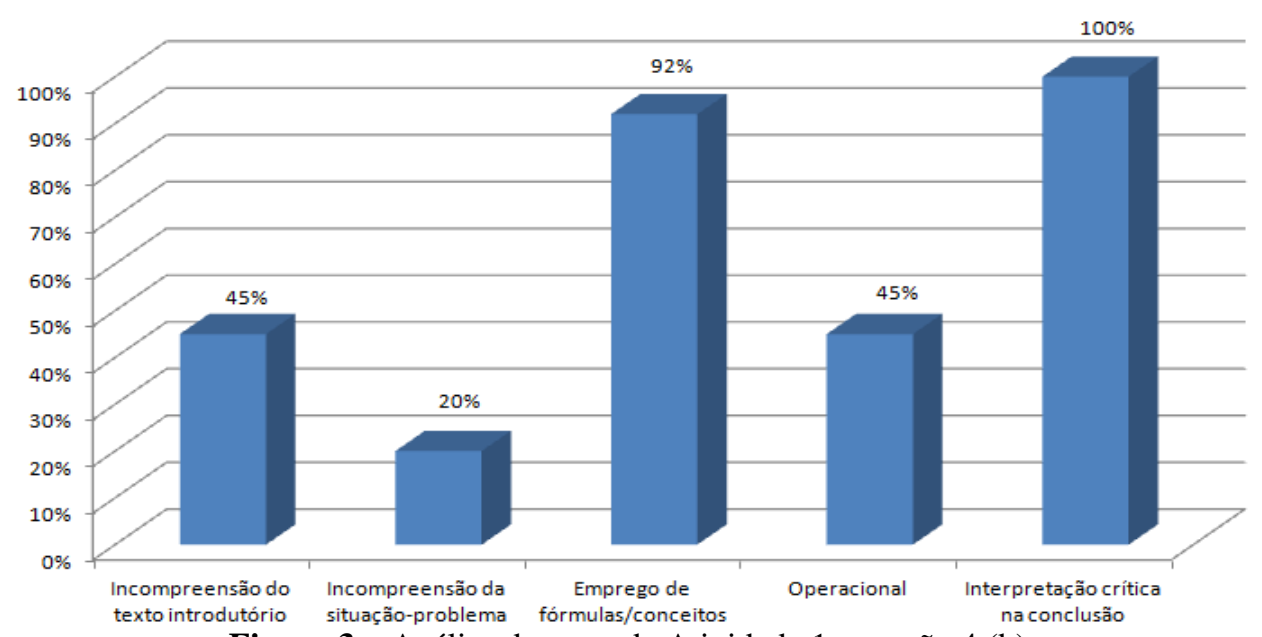

Figura 3 - Análise de erros da Atividade 1, questão 4 (b)

Fonte: Elaborado pelos autores (2013)

Esse item nos mostrou que os alunos não souberam estabelecer uma relação direta entre juros compostos e a função exponencial, o que pode revelar a forma discreta da abordagem dos conteúdos escolares.

Nos itens seguintes, as indagações serviam como simuladoras para ajudar a compreender o que acontece quando fazemos variar o capital aplicado, a taxa de juros ou o período de investimento, aplicando-os na fórmula de soma de termos de uma progressão geométrica finita.

c) Desenvolva uma fórmula para calcular o valor final que Antônio teria em 12 meses de seguidas aplicações e rendimentos, com base no conteúdo matemático citado no item anterior.

d) Desenvolva uma fórmula para calcular o valor final que Antônio teria em n meses de seguidas aplicações de C reais a uma taxa mensal de juros $i$.

e) E se Antônio aplicasse $R \$ 200,00$, na poupança que rende os mesmos 0,5\% ao mês durante um ano?

f) E se Antônio aplicasse $R \$ 100,00$, na poupança que rende os mesmos 0,5\% ao mês durante dois anos?

g) E se Antônio aplicasse $R \$ 100,00$, em uma aplicação de risco pré-fixada que rende $0,9 \%$ ao mês durante um ano?

h) Considere o caso em que Antônio queria fazer uma aplicação de um ano, mas estava em dúvida se faria pela poupança que rende 0,6\% ao mês, ou pelo CDB-DI que rende 0,8\% mensalmente, porém incidindo ainda um IRPF de $11 \%$ sobre seu lucro. Apresente a melhor aplicação para Antônio. 
i) Agora você é um analista de investimentos e vai prestar uma assessoria a Antônio, cite 3 possibilidades de melhorar o investimento do seu cliente, já que este deseja aplicar um valor mensal constante.

Nos itens que vão de $c$ ) até $i$ ), observamos na figura a seguir que, de forma geral, os alunos não interpretaram bem o enunciado dos itens e, demonstraram baixo índice de compreensão das fórmulas que tanto fizeram por decorar.

É uma situação inquietante, pois conhecem uma fórmula, mas não sabem o significado das variáveis e como se deduziu essa relação. $O$ fato de não se trabalhar a relação existente entre progressão geométrica e juros compostos dificulta a aplicação destes conceitos em situações econômico-financeiras, mesmo as mais simples, como planejar uma poupança.

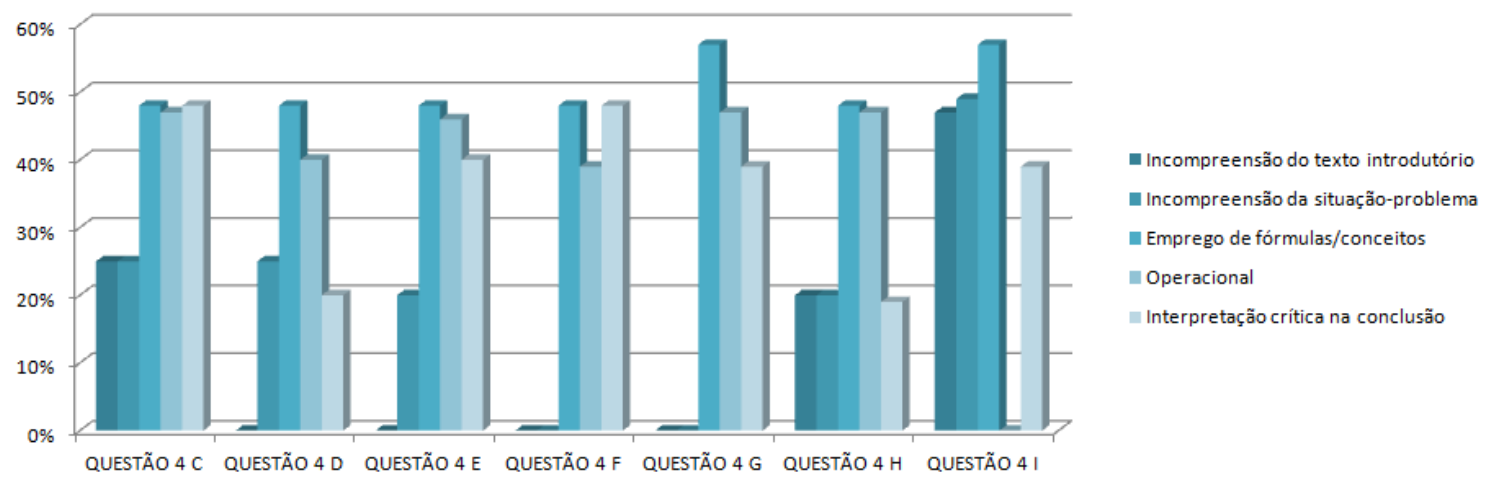

Figura 4 - Análise de erros da Atividade 1, questões 4 (c) até 4 (i)

Fonte: Elaborado pelos autores (2013)

Se observarmos na Figura 4 apenas os itens $h$ ) e $i$ ), constataremos que a incompreensão da situação-problema interferiu na utilização das fórmulas e dos cálculos e contribuiu para o baixo índice de acertos da interpretação crítica da conclusão. Com esses dados, podemos intervir na formação dos nossos alunos, repensando práticas de sala de aula que possibilitem correlacionar os conteúdos matemáticos entre si e/ou com temas sociais.

O ensino baseado em memorização de fórmulas é inútil para lidar com situações reais simples, como as que utilizamos nos itens citados.

As questões foram pensadas de forma que os alunos percebessem o significado de poupar, sua praticidade e o retorno, não só financeiro, mas na melhoria da qualidade de vida. A revista $\mathrm{EXAME}^{3}$ fez uma reportagem com o tema "Por que é mais importante poupar do que investir?", em que entrevistou André Massaro, especialista em finanças pessoais da MoneyFit. $\mathrm{O}$ autor afirmou que

quem tem uma vida financeira desregrada tem grandes chances de perder dinheiro ao entrar em um investimento. "É preciso antes de tudo ter uma organização

\footnotetext{
${ }^{3}$ REVISTA EXAME. Editora Abril, disponível em: <http://exame.abril.com.br/noticias/por-que-e-mais-importa nte-poupar-do-que-investir>. Acesso em: 20 jan. 2014.
} 
financeira para não perder dinheiro. E depois é preciso começar pelo básico, com aplicações apenas na poupança, no Tesouro Direto ou em um fundo de investimento. Aplicações mais complexas não são necessárias, em princípio", defende (REVISTA EXAME, 2014).

Essa atividade trouxe à tona a discussão sobre formas de enriquecimento fácil pelas perguntas sobre projeções para se ter o primeiro milhão e outras similares. Nesse momento, o professor perguntou aos alunos em quais condições mais reais possíveis poderíamos calcular como obter o primeiro milhão.

Os dados foram sendo apresentados e selecionados pelos próprios alunos, de forma questionadora, um a um, de maneira que para um trabalhador normal, fosse possível acumular um milhão de reais em alguns anos.

A sequência de atividades foi suficiente para lhes mostrar que o fator preponderante para que o dinheiro renda o suficiente para quem poupa é o tempo, pois as taxas de aplicações no mercado financeiro para pequenos e médios poupadores, atualmente, é de $1 \%$ ao mês ou para menos desse valor.

Essa consciência de que é preciso usar somente o excedente para investir, conforme o especialista André Massaro, só foi criada pelos alunos a partir dessa sequência de questões. Muitos achavam que os juros das aplicações eram bem maiores que os praticados, o que frustrou um pouco suas expectativas.

Alguns alunos levantaram outras formas de enriquecimento rápido, onde pessoas despreparadas são atraídas para investimentos mirabolantes e de grande retorno, como os "esquemas de pirâmide", onde alguns indivíduos, os primeiros a ingressarem, "se alimentam" dos que ficam na base e são os únicos a lucrar com essa estrutura.

Em meio a essas discussões uma aluna sintetizou bem o que essa atividade tinha por intenção: "O problema não está em se aventurar em investimentos e sim ter uma sanidade financeira que o possibilite então, usar o dinheiro excedente para tais fins, sem comprometer o seu orçamento" (Caderno de Anotações dos pesquisadores, 2013).

\section{Análise da questão 7 da atividade 2: seguro-desemprego}

A questão foi precedida de um texto detalhado que informava sobre "quanto vale $e$ quem tem direito ao seguro-desemprego", e perguntava:

Retomemos o caso de João que recebia de salário bruto o valor de $R \$ 1.600,00$, trabalhou por exatamente 2 anos e tinha plenas condições de recebimento do benefício na forma da lei. Quanto receberá de seguro-desemprego e por quanto tempo? 
Foram apresentadas as tabelas que informavam o valor do benefício (tabela 2) e a quantidade de parcelas a receber referentes ao período trabalhado (tabela 3).

Tabela 2 - Valor do benefício do seguro-desemprego segundo a faixa salarial

\begin{tabular}{|c|c|}
\hline Faixa salarial média & Valor do benefício \\
\hline Até R\$̦ 1.090,43 & Multiplica-se o salário médio por 0,8 . \\
\hline $\begin{array}{c}\text { De } \mathbf{R} \$ 1.090,44 \text { até } \\
\text { R\$ } 1.817,56\end{array}$ & $\begin{array}{l}\text { O que exceder R\$1.090,43 multiplica-se por 0,5 e soma-se a R\$ } \\
\qquad 872,74 .\end{array}$ \\
\hline Acima de $\mathbf{R} \$ 1.817,56$ & O valor da parcela será de $\mathrm{R} \$ 1.235,91$. \\
\hline
\end{tabular}

Fonte: Receita Federal (2013)

Tabela 3 - Parcelas a receber segundo o período trabalhado

\begin{tabular}{cc}
\hline $\begin{array}{c}\text { Quantidade de } \\
\text { parcelas a receber }\end{array}$ & $\begin{array}{r}\text { Relação aos meses trabalhados, se comprovado, nos últimos } 36 \\
\text { meses, vínculo empregatício de: }\end{array}$ \\
\hline 3 & no mínimo 6 meses e no máximo 11 meses. \\
4 & no mínimo 12 meses e no máximo 23 meses. \\
\hline
\end{tabular}

Fonte: Receita Federal (2013)

A tabela de erros apresentada a seguir mostra uma evolução dos alunos com relação à interpretação e compreensão da situação-problema e do texto que a precede, ocorrendo apenas erros operacionais, que os levaram a uma interpretação incorreta, pois estavam vinculadas.

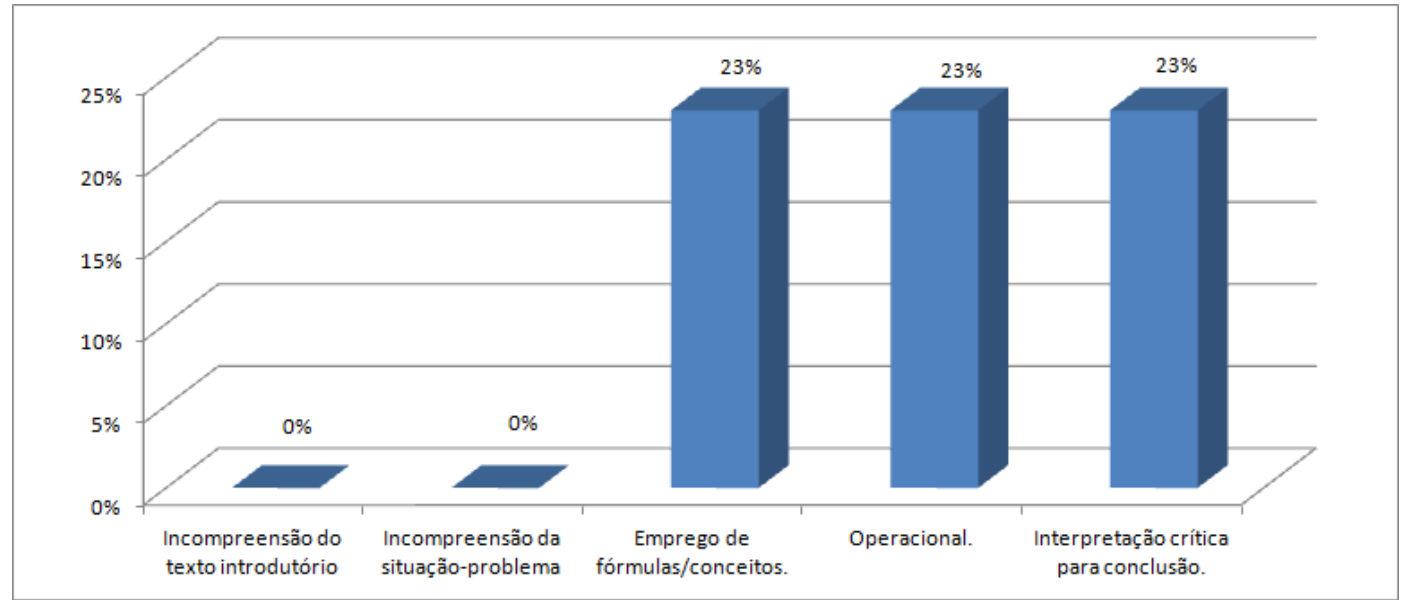

Figura 5 - Análise de erros da Atividade 2, Questão 7

Fonte: Elaborado pelos autores (2013)

Houve crescimento no número de acertos e uma evolução quanto à compreensão das situações-problema, o que nos retorna como fator positivo referente à sequência de atividades. 


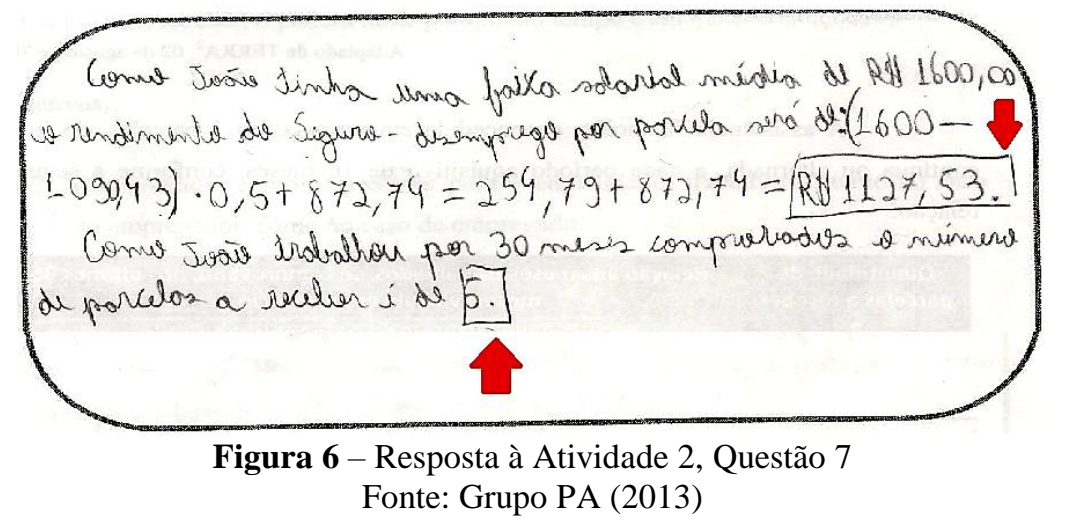

Reproduzindo a redação do extrato da Figura 6: "Como João tinha uma faixa salarial média de R\$ 1.600,00 o rendimento do Seguro-desemprego por parcela será de: (1600 $1.090,43) \cdot 0,5+872,74=254,79+872,74=\mathrm{R} \$ 1.127,53$. Como João trabalhou por 30 meses comprovados, o número de parcelas a receber é de 5.”

Com essa atividade, os alunos realizaram discussões sobre um tema diferente do conteúdo estritamente matemático. Também foram realizadas discussões éticas, quanto às malícias que envolvem o recebimento desse benefício, em detrimento do tempo mínimo de trabalho para adquiri-lo.

Mal instruídos por terceiros, trabalhadores fazem algumas escolhas que podem comprometer futuras oportunidades de trabalho e perda, ou postergação de alguns direitos, como a própria aposentadoria, no que corroboram Rosetti Jr. e Schimiguel (2009), afirmando que

a Matemática, e em especial a Matemática Comercial e Financeira, não pode continuar sendo um fator de exclusão do sistema escolar brasileiro, do mundo profissional e do ambiente corporativo, num contexto informatizado em que as linguagens nos veículos de informação são carregadas de signos lógicos quantitativos (ROSETTI JR. e SCHIMIGUEL, 2009, p. 11).

Atividades como estas podem promover alguma inclusão dos estudantes no mundo da Matemática Financeira, melhorando e disseminando o conhecimento em prol da melhoria da vida econômico-financeira da população brasileira. Contudo, há de se rever e adaptar os programas curriculares acerca da Matemática Financeira, para um tratamento de questões a permitir transitar pela Educação Financeira.

\section{Considerações finais}

Os principais resultados da pesquisa trazem parâmetros para enriquecer a Educação Financeira, uma área emergente e oriunda da Matemática Financeira e da Educação 
Matemática crítica, que permite ao estudante usar conceitos e cálculos da Matemática na sua vida social e econômica.

Os objetivos da investigação foram cumpridos com base no referencial teórico da resolução de problemas de Polya (2006), o qual começa com análise do enunciado até a retrospectiva dos resultados, a buscar coerência das respostas com os dados, numa contínua provocação reflexiva e crítica do estudante, o que ocorreu.

As atividades, a partir de situações problematizadoras, puderam mostrar ao estudante, segundo Echeverría e Pozo (1998), que é necessário buscar uma resposta, que emerge com uma atitude ativa e propositiva por meio da aprendizagem significativa, que não se resume em repetir proposições e soluções prontas.

Referenciando em Dante (2009), a percepção que tivemos em nossas observações acerca da fala dos alunos sobre a sequência de questões e distribuição dos conteúdos, apresentou um resultado satisfatório à nossa pesquisa, porque provocou um pensamento produtivo com a utilização de conceitos e proposições não só uso de algoritmos, buscando a eficácia da aprendizagem do estudante pela exploração, desafios e postura ativa nos procedimentos e exploração dos conceitos.

A construção das atividades referenciadas em Kistemann Jr. (2011), entre outros pesquisadores da Educação Financeira, trouxe em sua essência uma percepção da Matemática não só como disciplina de operacionalização de cálculos, mas como uma possibilidade da integração interdisciplinar da vivência de situações em diferentes campos cognitivos.

Perguntamos se o que fora aprendido seria útil ao aluno em alguma situação futura e, também, se lhe acrescentou algum conhecimento. Obtivemos muitas respostas positivas no sentido do que pretendíamos, isto é, promover a Educação Financeira de forma significativa a partir da resolução de problemas da Matemática Financeira. Pudemos verificar no desenvolvimento das atividades que na resolução das primeiras, os estudantes queriam apenas se ater aos cálculos financeiros, o que trouxe dificuldades, pois era necessário fazer interpretação das situações problematizadas. Mas, no decorrer do desenvolvimento das atividades, começaram a interpretar e analisar dados e parâmetros fornecidos nos problemas, o que melhorou sua desenvoltura.

Então, inicialmente, os estudantes acharam as atividades muito cansativas, mas, a partir da segunda, se envolveram de forma a questionar e trazer situações de seu próprio interesse para serem tratadas junto aos colegas e se adequaram à nova proposta de trabalho, em que as respostas não são dadas pelo professor, mas construídas por eles em conjunto e em meio à pesquisa, leitura e interpretação. 
Quando os alunos tiveram contato com essas situações financeiras apresentadas nas atividades, puderam se sentir mais seguros quanto a algumas situações do mundo econômicofinanceiro, apesar da ingenuidade quanto a suas projeções, própria dos jovens e facilmente percebida na fala de uma das duplas:

"Acreditamos que essa atividade nos proporcionou uma nova visão com relação à matemática financeira, principalmente no que diz respeito aos juros. Embora reconhecemos a utilidade da percepção que adquirimos hoje, esperamos ter recursos o suficiente para, no futuro, não necessitarmos de financiamentos de imóveis" (Grupo BF, Caderno de Anotações dos autores, 2013).

Dentre as expectativas da utilização do conhecimento adquirido, disseram que:

"Sim, será útil em situações de financiamento bancário para que consigamos escolher a melhor opção de pagamento, com os menores juros. Foi possível nos acrescentar uma noção de educação financeira para cálculos em situações futuras (financiamento de imóvel, automóvel ou carta de crédito)" (Grupo GM, Caderno de Anotações dos autores, 2013).

Os temas econômicos renderam boas discussões em sala e mobilizaram os alunos para que trouxessem informações em textos ou reportagens, principalmente da internet, para que servissem como norteadores para os debates, o que desmistificou qualquer anseio sobre o trabalho com resolução de problemas em sala de aula.

Quando fazemos uso de situações da interdisciplinaridade da matemática com outras ciências, encontramos uma série de dificuldades, seja por parte do aluno que precisa descrever, analisar, criticar e sintetizar, isto é exercitar habilidades diferentes do estudo mecânico e repetitivo, seja por parte do professor que tem de complementar sua formação para dialogar com outras áreas que não a de sua especialidade. Na pesquisa realizada, estas áreas seriam o conhecimento de finanças e de economia, com visão social e política.

Contudo, o aprendizado do professor e do estudante, numa aula ativa e de discussão é maior que na aula expositiva com uma breve explicação do professor, seguida de um exemplo para que os alunos o reproduzam, exaustivamente, como nas aulas tradicionais de apenas repasse de conteúdo.

Alcançamos o objetivo de identificar atividades que promovam uma compreensão das situações reais econômicas em Matemática Financeira, o que resultou em nosso produto, um Caderno de Atividades, que traz as questões analisadas e reestruturadas da pesquisa apresentadas na Dissertação da qual se originou este artigo.

Levantamos, para pesquisas futuras, alguns temas que possam ser debatidos dentro da nossa temática na Educação Básica, tanto no Ensino Fundamental como no Médio:

- Legislação trabalhista das empregadas domésticas

- De centavo em centavo podemos ficar ricos 
- Como alcançar o primeiro milhão

- Entender a tabela Price e suas aplicações

- O que são e as diferenças entre PGBL e VGBL?

- Questões tributárias como as do IRPF

Finalmente, cumprimos nosso objetivo da pesquisa que foi, primordialmente, fazer uma confluência da Matemática Financeira para a Educação Financeira, área emergente para os educadores matemáticos.

\section{Referências}

BRASIL. MEC. Parâmetros Curriculares Nacionais, Ensino Médio. Brasília, 1998. Disponível em <http://portal.mec.gov.br/seb/arquivos/pdf/ciencian.pdf>. Acesso em: 22 nov. 2016.

BRASIL. MEC. Parâmetros Curriculares Nacionais +, Ensino Médio. Brasília, 2007. Disponível em <http://www.sbfisica.org.br/arquivos/PCN_CNMT.pdf>. Acesso em: 22 nov. 2016.

BRASIL. MEC. Matriz de Referência do Novo ENEM. Brasília, 2009. Disponível em <http://portal.mec.gov.br/index.php?Itemid=310+enen.br>. Acesso em: 22 nov. 2016.

BRASIL. Estratégia Nacional de Educação Financeira - Plano Diretor da ENEF. Disponível em: $\langle$ https://www.bcb.gov.br/pre/pef/port/Estrategia_Nacional_Educacao_Financeira_ENEF.pdf $>$. Acesso em: 22 nov. 2016.

BRASIL. Guia de livros didáticos. PNLD 2012: Matemática. Brasília: Ministério da Educação, Secretaria de Educação Básica, 2012.

BRITO, R. R. Educação financeira: uma pesquisa documental crítica. 2012. 266f. Dissertação (Mestrado em Educação Matemática) - Programa de Pós-Graduação em Educação Matemática. Universidade Federal de Juiz de Fora, Juiz de Fora, 2012. Disponível em: <http:// www.ufjf.br/mestradoedumat/files/2011/05/DISSERTA\%C3\%87\%C3\%83O-REGINALDO-RAMOSBRITTO.pdf $>$. Acesso em: 22 nov. 2016.

CAMPOS, A. B. Investigando como a educação financeira crítica pode contribuir para tomada de decisões de consumo de jovens-indivíduos consumidores (JIC'S). 2013. 177f. Dissertação (Mestrado Profissional em Educação Matemática) - Programa de Pós-Graduação em Educação Matemática. Universidade Federal de Juiz de Fora, Juiz de Fora, 2013. Disponível em: <http:// www.ufjf.br/mestradoedumat/files/2011/05/Disserta\%C3\%A7\%C3\%A3o-Andre-Campos.pdf >. Acesso em: 22 nov. 2016.

CAMPOS, M. B. Educação financeira na matemática do ensino fundamental: uma análise da produção de significados. 2012. 179f. Dissertação (Mestrado Profissional em Educação Matemática) Programa de Pós-Graduação em Educação Matemática. Universidade Federal de Juiz de Fora, Juiz de Fora, 2012. Disponível em:

<http://www.ufjf.br/mestradoedumat/files/2011/05/Disserta\%C3\%A7\%C3\%A3o-_-MarceloBergamini-Campos.pdf >. Acesso em: 22 nov. 2016.

DANTE, L. R. Formulação e resolução de problemas de matemática: teoria e prática. 1. ed. São Paulo: Ática, 2009. 192p. 
DINIZ, Maria Ignez. Resolução de Problemas e comunicação. In: SMOLE, Kátia Stocco e DINIZ, Maria Ignez. Ler, escrever e resolver problemas: habilidades básicas para aprender matemática. Porto Alegre: Artmed Editora, 2001. p. 87-97.

ECHEVERRÍA, M. D. P. P.; POZO, J. I. A solução de problemas: aprender a resolver, resolver para aprender. $2^{\mathrm{a}}$ ed. Porto Alegre: Artes Médicas (Artmed), 1988. 177p.

KISTEMANN JR., M. A. Sobre a produção de significados e a tomada de decisão de indivíduosconsumidores. 2011. 540f. Tese (Doutorado em Educação Matemática) - Programa de Pós-graduação em Educação Matemática, Instituto de Geociências De Ciências Exatas, Universidade Estadual Paulista, Rio Claro, 2011.

LIMA, Cristiane Bahia; SÁ, Ilydio Pereira de. Matemática Financeira no Ensino Fundamental. Revista TECCEN - Universidade Severino Sombra, v. 3, n. 1, abr. 2010.

NASSER, Lilian \& Projeto Fundão. Matemática financeira para a escola básica: uma abordagem prática e visual. Instituto de Matemática, UFRJ, 2010.

ONUCHIC, L. R.; ALLEVATO, N. S. G. Novas Reflexões sobre o ensino-aprendizagem de Matemática através da resolução de problemas. In: BICUDO, Maria A. V. e BORBA, Marcelo de C. Org. Educação Matemática: pesquisa em movimento. São Paulo: Cortez, 2012, p. 232-252.

POLYA, G. A arte de resolver problemas. $2^{\mathrm{a}}$ ed. Rio de Janeiro; Interciência, 2006. 203p.

PONTE, J. P. BOAVIDA, A. M., Graça, M. e ABRANTES, P. Didáctica da matemática: Ensino secundário. Lisboa: Ministério da Educação, Departamento do Ensino Secundário. Lisboa: DES do ME, 1997. p. 1-25. Disponível em: <http://www.educ.fc.ul.pt/docentes/jponte/fdm/textos/PonteBoavida-Graca-Abrantes(Cap4-Dinamica).pdf>. Acesso em: 22 nov. 2016.

OLIVEIRA, R. S. O. Educação Financeira em sala de aula na perspectiva da etnomatemática. 2007. 135f. Trabalho de Conclusão do Curso (Graduação em Pedagogia) - Faculdade de Ciências. Universidade Estadual Paulista "Júlio de Mesquita Filho". Bauru, 2007.

PUCCINI, E. C. Matemática financeira. Projeto universidade aberta. 2007. Disponível em: <http://docplayer.com.br/889801-Matematica-financeira-ernesto-coutinho-puccini.html>. Acesso em: 22 nov. 2016.

RESENDE, A. F. A Educação financeira na educação de jovens e dultos: uma leitura da produção de significados financeiro-econômicos de dois indivíduos-consumidores. 2013. 165f. Dissertação (Mestrado Profissional em Educação Matemática) - Programa de Pós-Graduação em Educação Matemática, Universidade Federal de Juiz de Fora, Juiz de Fora, 2012. Disponível em: <http://www.ufjf.br/mestradoedumat/files/2011/05/DISSERTA\%C3\%87\%C3\%83O-AMANDAFABRI-DE-RESENDE.pdf>. Acesso em: 22 nov. 2016.

ROSSETI JR., H.; SCHIMIGUEL, J. Educação matemática financeira: conhecimentos financeiros para a cidadania e inclusão. Revista Científica Internacional: Inter Science Place, ano 2, n. 9, p. 113. Out/nov. 2009. 